\title{
Isentropic Pressure and Mountain Torques
}

\author{
JOSEPH EGGER \\ Meteorologisches Institut, Universität München, Munich, Germany \\ Klaus-Peter HoinKa \\ Institut für Physik der Atmosphäre, DLR, Oberpfaffenhofen, Germany
}

(Manuscript received 4 November 2008, in final form 12 March 2009)

\section{ABSTRACT}

\begin{abstract}
The relation of pressure torques and mountain torques is investigated on the basis of observations for the polar caps, two midlatitude and two subtropical belts, and a tropical belt by evaluating the lagged covariances of these torques for various isentropic surfaces. It is only in the polar domains and the northern midlatitude belts that the transfer of angular momentum to and from the earth at the mountains is associated with pressure torques acting in the same sense. The situation is more complicated in all other belts. The covariances decline with increasing potential temperature (height). The role of both torques in the angular momentum budget of a belt is discussed.
\end{abstract}

\section{Introduction}

Angular momentum budgets have a long tradition in general circulation research (Lorenz 1967; Gallimore and Johnson 1981; Oort and Peixoto 1983; Johnson 1989) as a tool to understand the zonal circulation of the atmosphere. This technique is particularly attractive because axial angular momentum (AAM) changes are described by a conservation equation where the AAM of a zonal annulus can be altered only by fluxes of AAM through its boundaries and by torques. Mountain and friction torques are the main torques to be included if height and isobaric coordinates are used in the analysis. They act at the earth's surface. If, however, isentropic coordinates are chosen, there are vertical fluxes due to the heating but also internal atmospheric torques, the pressure torques, which are important.

While the atmospheric "response" to mountain and friction torques attracted much attention, there was so far little interest in the isentropic pressure torques (see Egger et al. 2007 for a review). In particular, the relation of mountain and pressure torques has not been investigated at all. One may argue that results should not differ too much from those of traditional Eulerian analyses

Corresponding author address: Joseph Egger, Meteorological Institute, University of Munich, Theresienstr. 37, 80333 Munich, Germany.

E-mail: j.egger@Irz.uni-muenchen.de because the underlying physical processes are the same. However, isentropic analysis involves specific features (see Andrews 1983) as can be seen by looking at the zonally and vertically integrated AAM equation in isentropic coordinates:

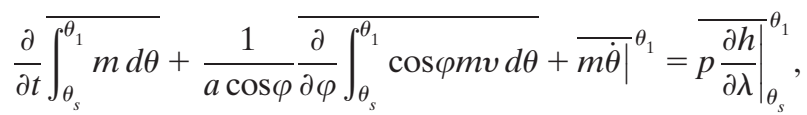

where

$$
m=-g^{-1} \frac{\partial p}{\partial \theta}(u+\Omega a \cos \varphi) a \cos \varphi
$$

is the axial angular momentum per unit volume, $\theta_{s}$ is the surface potential temperature, and $\theta_{1}$ is a constant potential temperature. Hence (1.1) is the budget of an atmospheric layer extending from the surface to the isentropic surface $\theta=\theta_{1}$. The bar in (1.1) stands for a zonal integral and the term on the right-hand side is the difference of the pressure torque:

$$
T_{p}^{*}\left(\theta_{1}\right)=\overline{p_{1} \frac{\partial h_{1}}{\partial \lambda}}
$$

per unit width acting at the surface $\theta=\theta_{1}$ and the "mountain torque": 


$$
T_{m}^{*}=\overline{p_{s} \frac{\partial h}{\partial \lambda}}
$$

per unit width, where $h_{1}$ is the height of the upper isentropic surface and $h$ is the topographic profile. The derivation of (1.1) invokes the surface potential temperature equation:

$$
\frac{\partial}{\partial t} \theta_{s}+\mathbf{v}_{s} \cdot \nabla \theta_{s}=\dot{\theta}_{s}
$$

where $\mathbf{v}_{s}$ is the wind at the surface (e.g., Egger and Hoinka 2008). The friction torque is neglected in (1.1) because we will consider mountain torques only. Thus isentropic AAM analysis differs substantially from standard coordinate analyses because heating is able to transport angular momentum across the top surface $\theta=\theta_{1}$. Pressure torques act in addition. Moreover, $\theta$ surfaces are sloping strongly in the meridional directions. This affects the role of the meridional transports. It is therefore not so obvious what to expect for the relation of pressure and mountain torques that must be explored by analyzing mountain torque events. Note that the torques (1.3) and (1.4) represent the same physical mechanism. The pressure is acting on corrugated surfaces.

The mechanisms behind the pressure torques in general have been considered by Johnson and Downey (1975), Townsend and Johnson (1985), and Johnson (1989), who pointed out that the structure of baroclinic systems with their westward tilt with increasing height implies positive pressure torques. Juckes et al. (1994) argued along similar lines that there is a close relation between pressure torques and transient meridional heat transports. However, there appears to be no generally accepted model for the impact of mountains on pressure torques so that we have to turn to data to learn more about that. As for mountain torque events it has been found by Egger and Hoinka (2004) for the global situation that they are short lived and felt quickly even in the stratosphere. Mountain torque events for individual belts are always linked to meridional angular momentum transports across the boundaries of the belts (Egger and Hoinka 2005). This implies that the related pressure torques per belt will decrease with increasing $\theta_{1}$.

In principle, isentropic data analysis is to be preferred when compared to conventional analyses where vertical motions are needed to estimate the vertical AAM fluxes. These vertical motions are not directly observable in the atmosphere. In particular, estimates of the vertical flux of the so-called mass term $\sim(\partial p / \partial \theta) \Omega a \cos ^{2} \varphi$ in (1.2) require extreme accuracy so that investigations of the relation of mountain torques and vertical angular momentum fluxes are plagued by uncertainties. On the other hand, the evaluation of pressure torques is fairly straightforward and accurate. There is, however, the caveat that modern analysis schemes are not based on isentropic coordinates so that interpolations are required that reduce the accuracy. Moreover estimates of heating are notoriously difficult but are not needed here. It is the main purpose of this paper to provide an observational analysis of the typical variations of pressure torques during mountain torque events. We have to look for correlations of both torques for various values of $\theta_{1}$. Do the torques generally act in the same sense? Which torque is more important? How does the answer to these questions vary with latitude?

\section{Results}

The results to be presented are based on 40-yr European Centre for Medium-Range Weather Forecasts Re-Analysis (ERA-40) data for the years 1958-2001. The height and pressure of selected $\theta$ surfaces are daily means, and the torques

$$
\begin{aligned}
T_{p}\left(\theta_{1}, \varphi_{1}, \varphi_{2}\right) & =\int_{\varphi_{1}}^{\varphi_{2}} \overline{p_{1} \frac{\partial h_{1}}{\partial \lambda}} a d \varphi \quad \text { and } \\
T_{m}\left(\varphi_{1}, \varphi_{2}\right) & =-\int_{\varphi_{1}}^{\varphi_{2}} \overline{p_{s} \frac{\partial h}{\partial \lambda}} a d \varphi
\end{aligned}
$$

are determined for seven belts where the belts 1 (latitude $\left.\varphi_{1}=90^{\circ} \mathrm{S}, \varphi_{2}=72^{\circ} \mathrm{S}\right)$ and $7\left(\varphi_{1}=72^{\circ} \mathrm{N}, \varphi_{2}=90^{\circ} \mathrm{N}\right)$ represent the polar caps, the belts $2\left(\varphi_{1}=58^{\circ} \mathrm{S}, \varphi_{2}=\right.$ $\left.40^{\circ} \mathrm{S}\right)$ and $6\left(\varphi_{1}=40^{\circ} \mathrm{N}, \varphi_{2}=58^{\circ} \mathrm{N}\right)$ are at midlatitudes, the belts $3\left(\varphi_{1}=33^{\circ} \mathrm{S}, \varphi_{2}=15^{\circ} \mathrm{S}\right)$ and $5\left(\varphi_{1}=15^{\circ} \mathrm{N}, \varphi_{2}=\right.$ $\left.33^{\circ} \mathrm{N}\right)$ represent the subtropics, and belt $4\left(\varphi_{1}=9^{\circ} \mathrm{S}\right.$, $\varphi_{2}=9^{\circ} \mathrm{N}$ ) covers the inner tropics. Pressure torques are evaluated for various $\theta$ surfaces that cover the troposphere and lower stratosphere. We adopt in (2.1) the convention that a positive pressure torque adds AAM to the layer underneath. It would be consistent to have positive torques to act also downward at the lower boundary, but the sign of the mountain torque is established so firmly that we decided to use the standard negative sign in (2.2) instead of the positive one in (1.4).

The evaluation of $T_{p}$ becomes problematic when the orography intersects the $\theta_{1}$ surface. In principle, the right-hand side of (1.1) can be adapted to this situation. However, the interpolations needed to calculate the additional terms cannot be carried out at the required level of accuracy. It appears better to replace the torque term in (1.1) below the topography by that at the $\theta$ level available just above it.

The covariance of a leading variable $b$ and a further variable $c$ at lag $\tau$ is denoted by $C(b, c \mid \tau)$. In what follows 
TABLE 1. Standard deviation of the mountain torque $\left(T_{m}\right)$ and the pressure torque in Hadley in JJA/DJF for all belts. The isentropic surfaces are indicated on the left.

\begin{tabular}{|c|c|c|c|c|c|c|c|}
\hline \multirow[b]{2}{*}{ Lat } & \multicolumn{3}{|c|}{ Southern Hemisphere (SH) } & \multirow{2}{*}{$\frac{\mathrm{SH}-\mathrm{NH}}{9^{\circ} \mathrm{S}-9^{\circ} \mathrm{N}}$} & \multicolumn{3}{|c|}{ Northern Hemisphere (NH) } \\
\hline & $90^{\circ}-72^{\circ}$ & $58^{\circ}-40^{\circ}$ & $33^{\circ}-15^{\circ}$ & & $15^{\circ}-33^{\circ}$ & $40^{\circ}-58^{\circ}$ & $72^{\circ}-90^{\circ}$ \\
\hline Belt No. & 1 & 2 & 3 & 4 & 5 & 6 & 7 \\
\hline $370 \mathrm{~K}$ & $0.4 / 0.3$ & $3.5 / 3.0$ & $1.6 / 1.5$ & $0.5 / 0.6$ & $1.4 / 2.2$ & $1.8 / 4.9$ & $0.2 / 0.8$ \\
\hline $350 \mathrm{~K}$ & $0.5 / 0.3$ & $4.4 / 4.6$ & $3.5 / 3.6$ & $0.8 / 1.1$ & $3.4 / 4.7$ & $3.9 / 6.2$ & $0.3 / 0.9$ \\
\hline $330 \mathrm{~K}$ & $0.7 / 0.5$ & $6.2 / 10.9$ & $9.5 / 6.2$ & $0.7 / 1.1$ & $3.5 / 10.0$ & $9.8 / 8.8$ & $0.6 / 1.1$ \\
\hline $320 \mathrm{~K}$ & $0.8 / 0.6$ & $10.9 / 16.1$ & $9.5 / 4.5$ & $0.5 / 0.6$ & $3.5 / 10.8$ & $10.9 / 15.2$ & $1.4 / 1.2$ \\
\hline $310 \mathrm{~K}$ & 1.0/0.9 & $20.4 / 17.9$ & $9.5 / 4.3$ & $0.6 / 0.7$ & $3.8 / 8.7$ & $10.5 / 23.2$ & $2.1 / 1.5$ \\
\hline $300 \mathrm{~K}$ & $1.7 / 1.5$ & 26.9/18.4 & $9.4 / 6.1$ & $1.9 / 2.0$ & $4.9 / 9.0$ & $10.7 / 28.1$ & $2.2 / 2.4$ \\
\hline $295 \mathrm{~K}$ & 2.3/1.6 & 28.1/18.4 & $-1-$ & $-1-$ & $-1-$ & $10.1 / 29.5$ & $2.2 / 3.0$ \\
\hline$T_{m}$ & $3.7 / 1.9$ & 1.6/1.1 & $10.6 / 7.6$ & $2.4 / 2.7$ & $4.4 / 8.7$ & $5.4 / 9.3$ & $1.3 / 2.3$ \\
\hline
\end{tabular}

the covariances $C\left(T_{m}, T_{p} \mid \tau\right)$ are presented for these seven belts and for the selected $\theta$ surfaces that cover the troposphere and lower stratosphere. It is convenient to normalize the mountain torques by their respective standard deviations so that the covariances have the unit Hadley $\left(1\right.$ Hadley $\left.=10^{18} \mathrm{~J}\right)$ and may also be called regressions. The standard deviation of the mountain torque is largest in belt 3 in June-August (JJA; see Table 1). In contrast, there is little variability in the neighboring southern midlatitude belt 2 . The standard deviations of the pressure torques decrease rapidly with increasing $\theta$ (Table 1 ) for $\theta \geq 320 \mathrm{~K}$. The tropical belts exhibit almost no variability. Maximum activity is seen in the midlatitude belts in the respective winter season.

Mean values of mountain and pressure torques mostly at $\theta=295 \mathrm{~K}$ are presented in Table 2. This isentropic surface is close to the maximum of positive torques (Johnson 1989; Egger and Hoinka 2008). Mean mountain torques are negative at midlatitudes and positive elsewhere as is well known (e.g., Oort and Peixoto 1983). The midlatitude pressure torques at $\theta=295 \mathrm{~K}$ almost dwarf the mountain torques. The dominance of the pressure torque is less pronounced in the subtropical belts.

\section{a. Polar caps}

The covariances of mountain and pressure torques for Southern Hemisphere winter (JJA) are displayed in Fig. 1 for the Antarctic belt and $295 \mathrm{~K} \leq \theta \leq 370 \mathrm{~K}$. Also given is the autocovariance of the mountain torque. The decay of this autocovariance is fairly rapid as is well known from earlier work (e.g., Egger et al. 2007) but with a small secondary maximum near $\tau \sim 3$ days. The decay of the covariances is almost as fast. The covariances are only slightly asymmetric with respect to $\tau \sim 0$. Pressure torques are somewhat larger for negative lags. The covariances are nearly always negative, at least for lags $\leq 5$ days. That means that part of the AAM transferred to the earth at the mountains is made available by pressure torques. In particular, there is a good dynamical connection between the perturbations near the ground and even those in the stratosphere. The torques become, of course, smaller and smaller the larger $\theta$ is (see also Table 1 ), but the correlation coefficients of mountain and pressure torques vary little with height. We find values of -0.4 for $\theta=295 \mathrm{~K}$ and -0.35 for $\theta=370 \mathrm{~K}$. Since the AAM of a layer between two isentropic surfaces $\theta=\theta_{1}$ and $\theta=\theta_{2}$ responds to the difference of pressure torques at $\theta_{1}$ and $\theta_{2}$, we learn from Fig. 1 that the AMM reacts to mountain torques even in the stratosphere.

In December-February (DJF), amplitudes of the covariances are smaller (not shown), of course, but the basic characteristics are the same as in Fig. 1.

The autocovariance of the mountain torque in the Arctic belt is very similar to that in Antarctica (Fig. 2) but the cross covariances $C\left(T_{m}, T_{p} \mid \tau\right)$ deviate significantly, with a minimum near $\tau=-1$ day and vanishing values near $\tau=1$ day. Thus, Fig. 2 suggests that the

TABLE 2. Time-mean values of the mountain torque (first entry) and the pressure torque (second entry) at the lowest $\theta$ surface available $(\theta=295 \mathrm{~K}$ in all belts except the tropical ones where $\theta=300 \mathrm{~K})$ in Hadley in JJA and DJF.

\begin{tabular}{|c|c|c|c|c|c|c|c|}
\hline \multirow[b]{2}{*}{ Lat } & \multicolumn{3}{|c|}{ SH } & \multirow{2}{*}{$\frac{\mathrm{SH}-\mathrm{NH}}{9^{\circ} \mathrm{S}-9^{\circ} \mathrm{N}}$} & \multicolumn{3}{|c|}{$\mathrm{NH}$} \\
\hline & $90^{\circ}-72^{\circ}$ & $58^{\circ}-40^{\circ}$ & $33^{\circ}-15^{\circ}$ & & $15^{\circ}-33^{\circ}$ & $40^{\circ}-58^{\circ}$ & $72^{\circ}-90^{\circ}$ \\
\hline Belt No. & 1 & 2 & 3 & 4 & 5 & 6 & 7 \\
\hline JJA & $2.1 / 0.6$ & $-0.6 / 77.0$ & $-0.7 / 27.4$ & $5.3 /-4.0$ & $-1.8 / 10.0$ & $-5.5 / 23.9$ & $0.3 / 2.5$ \\
\hline DJF & $0.8 / 0.9$ & $-2.2 / 52.0$ & $-7.5 / 16.2$ & $1.8 /-2.1$ & $8.5 / 20.9$ & $-6.9 / 25.7$ & $1.0 / 1.4$ \\
\hline
\end{tabular}




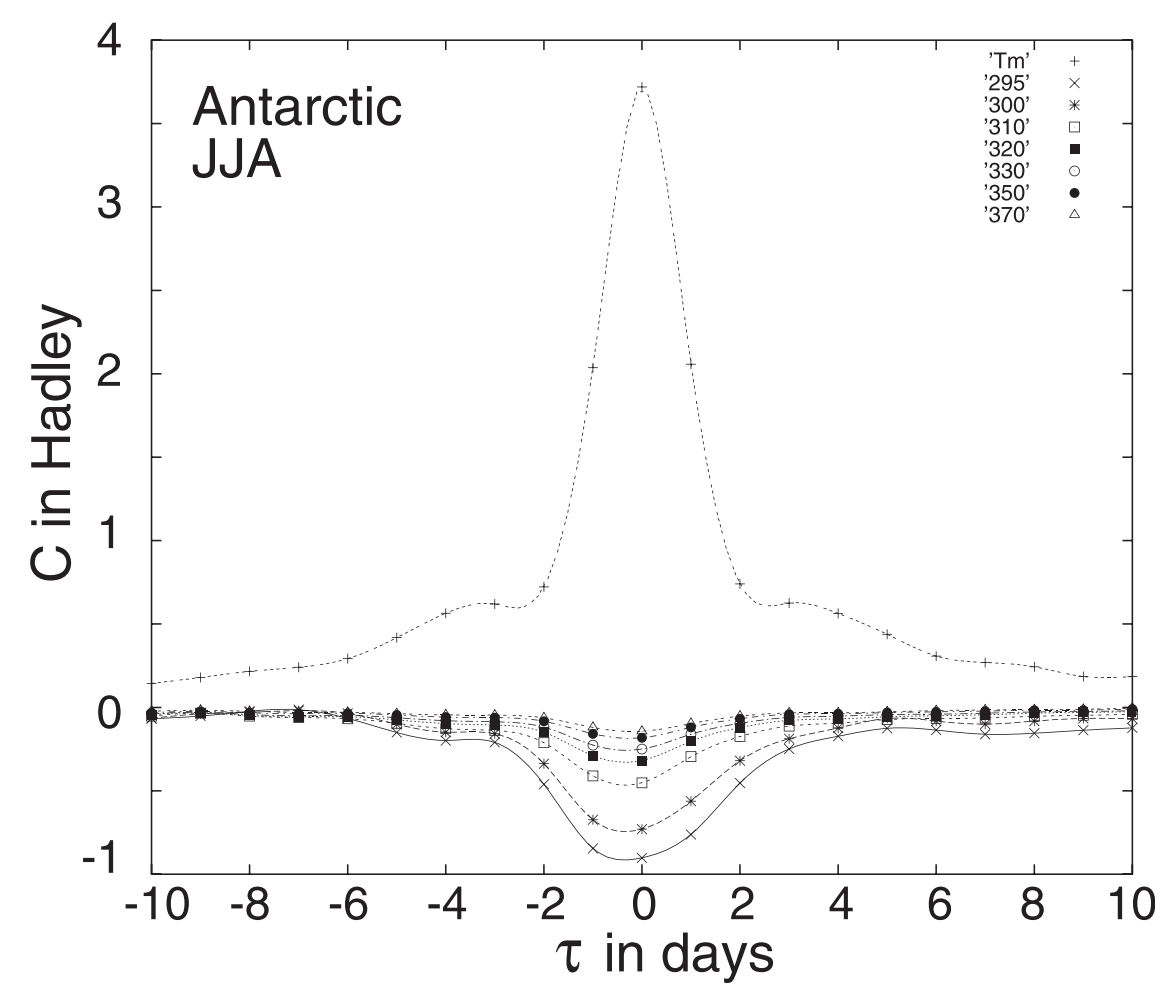

FIG. 1. Cross covariance $C\left[T_{m}, T_{p}(\theta) \mid \tau\right]$ of the Antarctic belt in Hadley in JJA where the mountain torque is normalized by its standard deviation as a function of lag $\tau$ in days. The symbol " 295 " stands for the isentropic surface $\theta=295 \mathrm{~K}$, etc. Also given is the autocovariance of the mountain torque "Tm" of the Antarctic belt in Hadley (normalized).

pressure torques transfer angular momentum downward before the mountain torque peaks. Again, there is good vertical coherence.

\section{b. Midlatitude belts}

The standard deviation of 1.6 Hadley of the mountain torque in southern midlatitude belt 2 (JJA) is relatively small (Table 1). The variability of the pressure torque is very large, with a standard deviation of $\sim 20$ Hadley (see Table 2), but the covariances of both torques are very small and positive (Fig. 3), at least near the surface and in winter. Correlation coefficients are $\sim 0.1$ near the surface and become negative and very small higher up. Thus, there is hardly any link between the two torques. The mountains play a minor role in the AAM budget of this belt.

The standard deviation of the mountain torque is fairly large (9.2 Hadley; DJF) in northern belt 6 . The structure of the covariance functions (Fig. 4) is somewhat more complicated than has been seen so far in that there are secondary minima near $\tau=-3$ days and also for $\tau=$ 1 day in the midtroposphere and near the ground. The correlation coefficients are small, and we observe again a decrease of the covariances with increasing potential temperature. Thus, Fig. 4 suggests that baroclinic waves are weakened when crossing mountains to recover afterward. In particular, the meridional heat transports appear to be reduced. Although the interaction of baroclinic systems with mountains attracted considerable attention [see Czarnetzki and Johnson (1996) and Davis (1997) for reviews], as stated above, no simple scheme emerged that would help us to better understand these curves.

\section{c. Subtropical belts}

The mountain torque variance in belt 3 is very large, but it is only for $\theta_{1}=300 \mathrm{~K}$ that we find negative covariances (Fig. 5). Higher up, the covariances tend to be positive near $\tau \sim 0$. This suggests that meridional transports in the lower troposphere are very important as is presumably the heating (see also section 3). The situation in the northern subtropical belt is even more surprising (Fig. 6) because the pressure torque covariances are very small and mainly positive. There is no downward transfer of AAM by the pressure torques to balance the mountain torques.

\section{d. Tropical belt}

Pressure torques are small in the tropical belt, with a standard deviation of $\sim 1$ Hadley and mean values from 


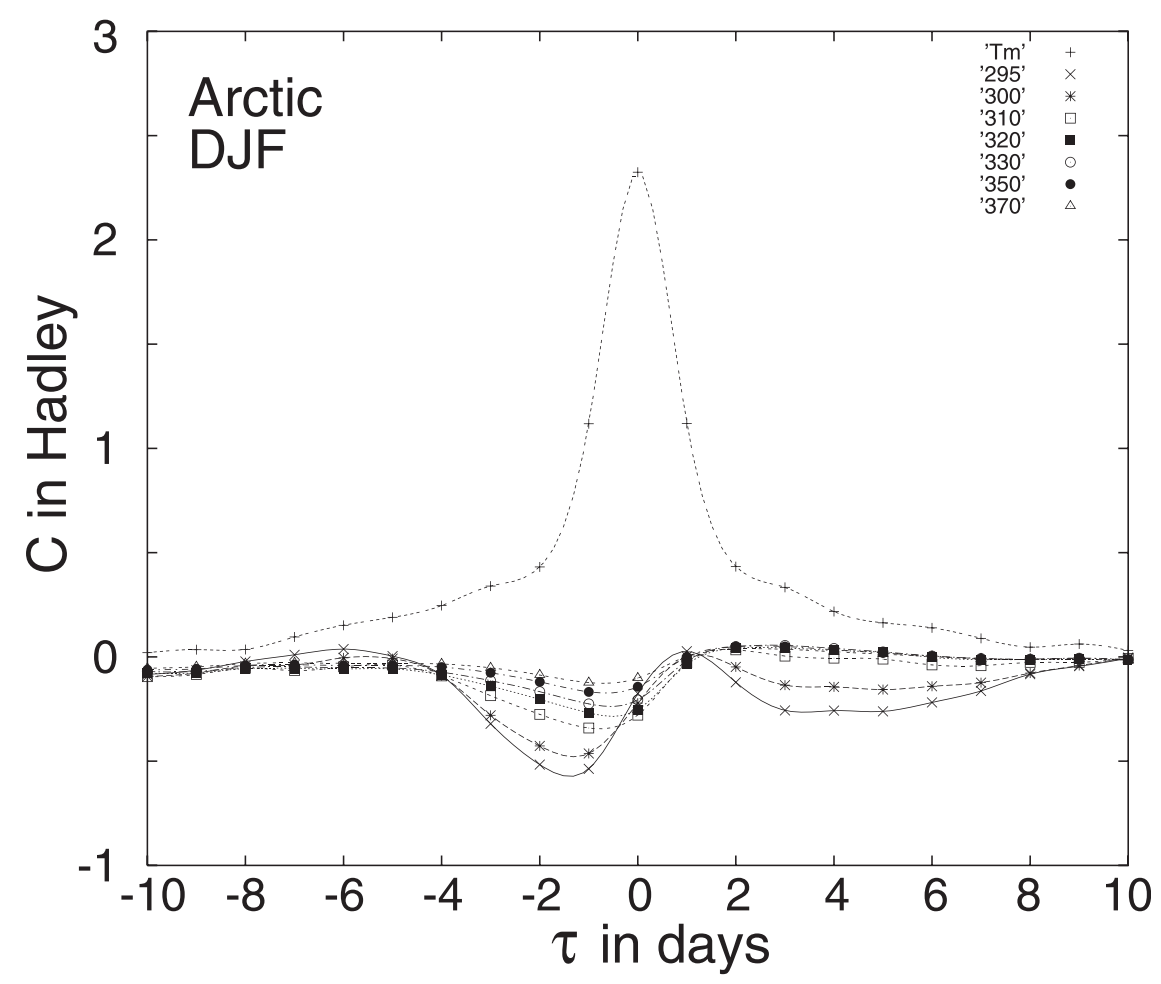

FIG. 2. As in Fig. 1, but for the Arctic belt in DJF.

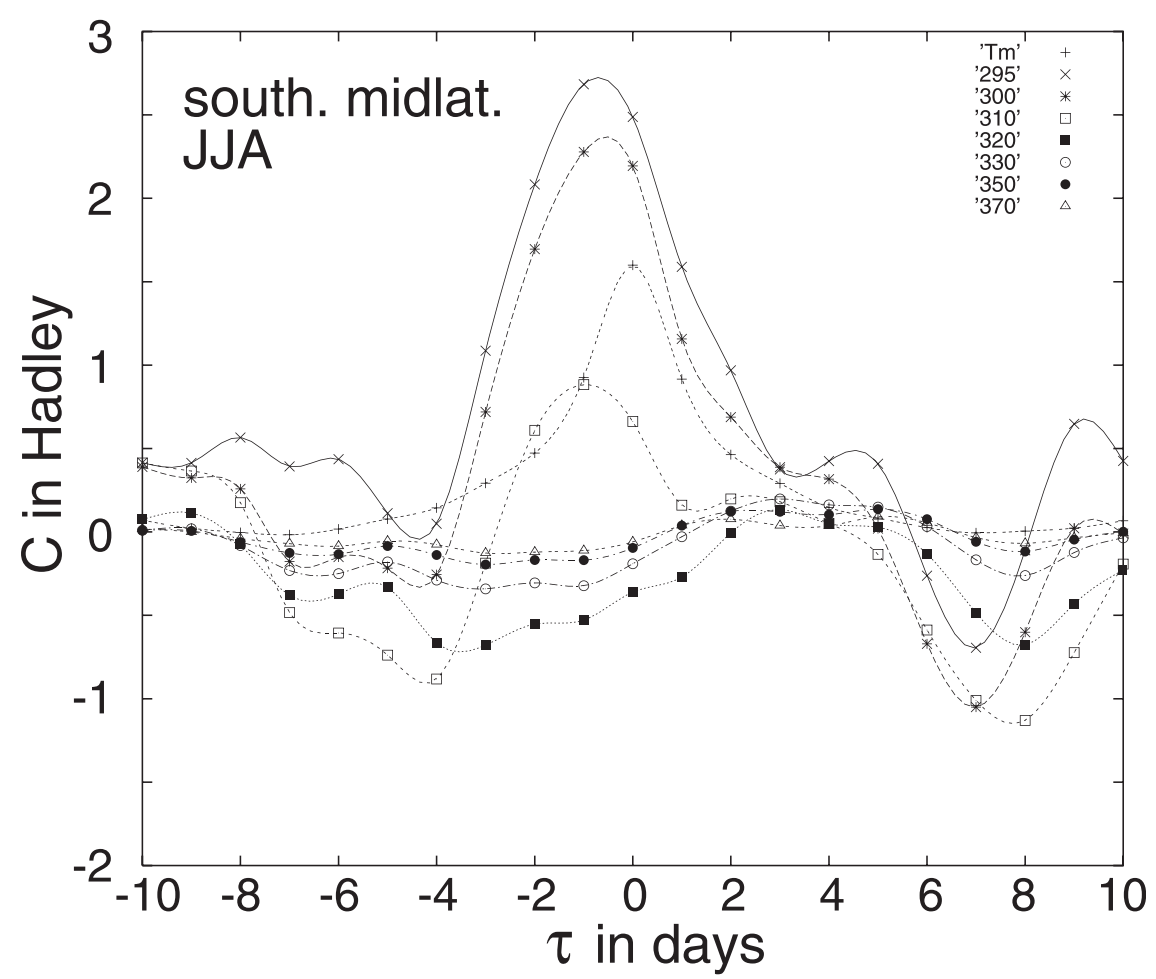

FIG. 3. As in Fig. 1, but for the southern midlatitude belt in JJA. 


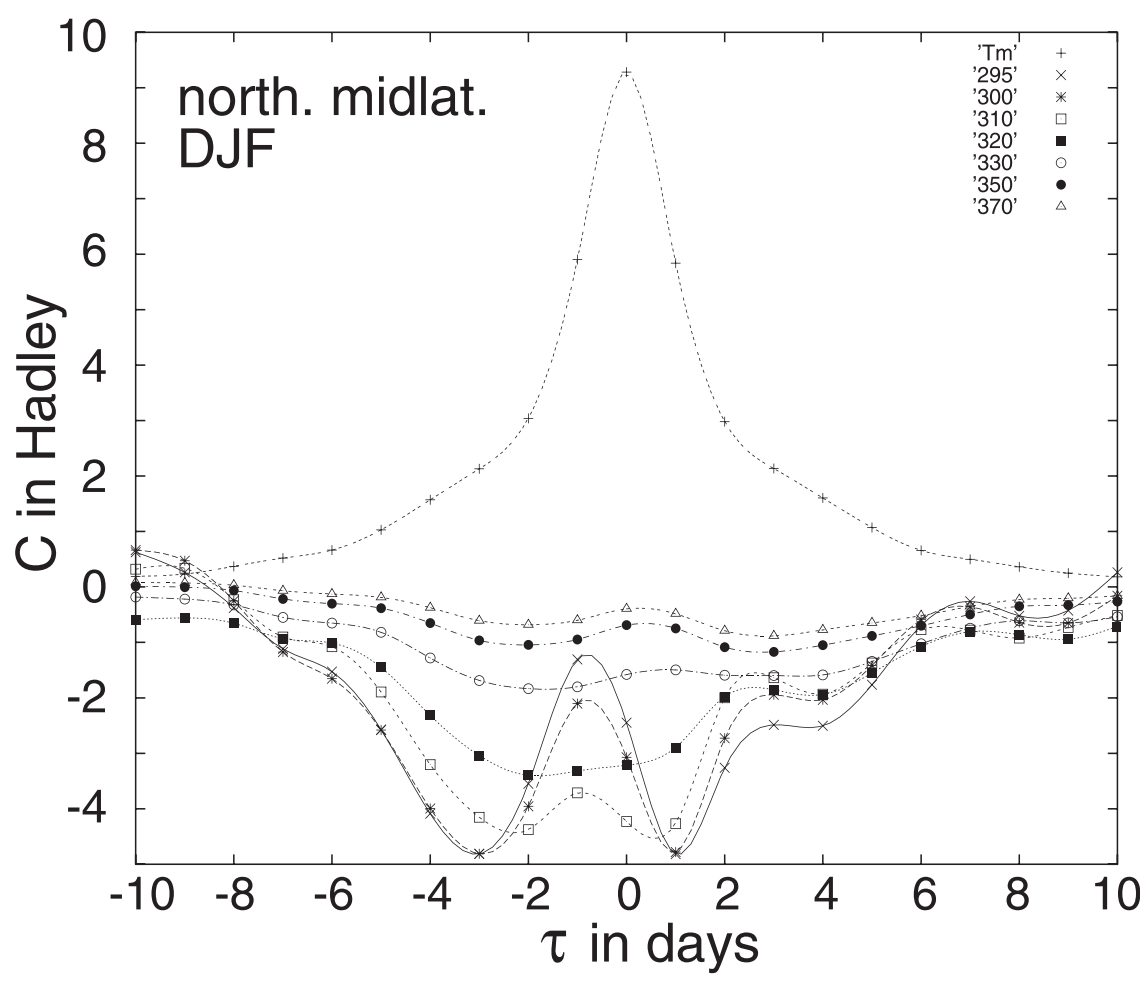

FIG. 4. As in Fig. 1, but for the northern midlatitude belt in DJF.

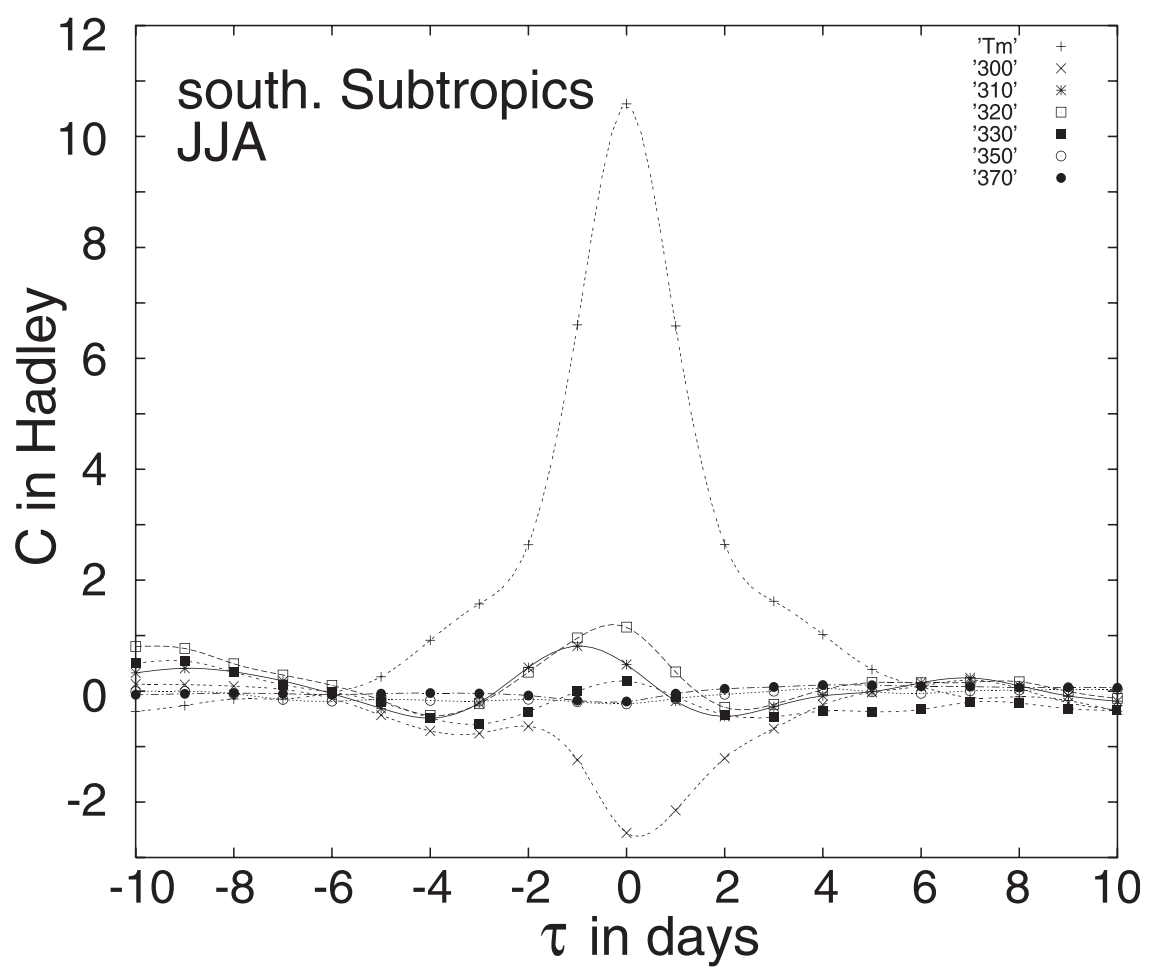

FIG. 5. As in Fig. 1, but for the southern subtropical belt in JJA. 


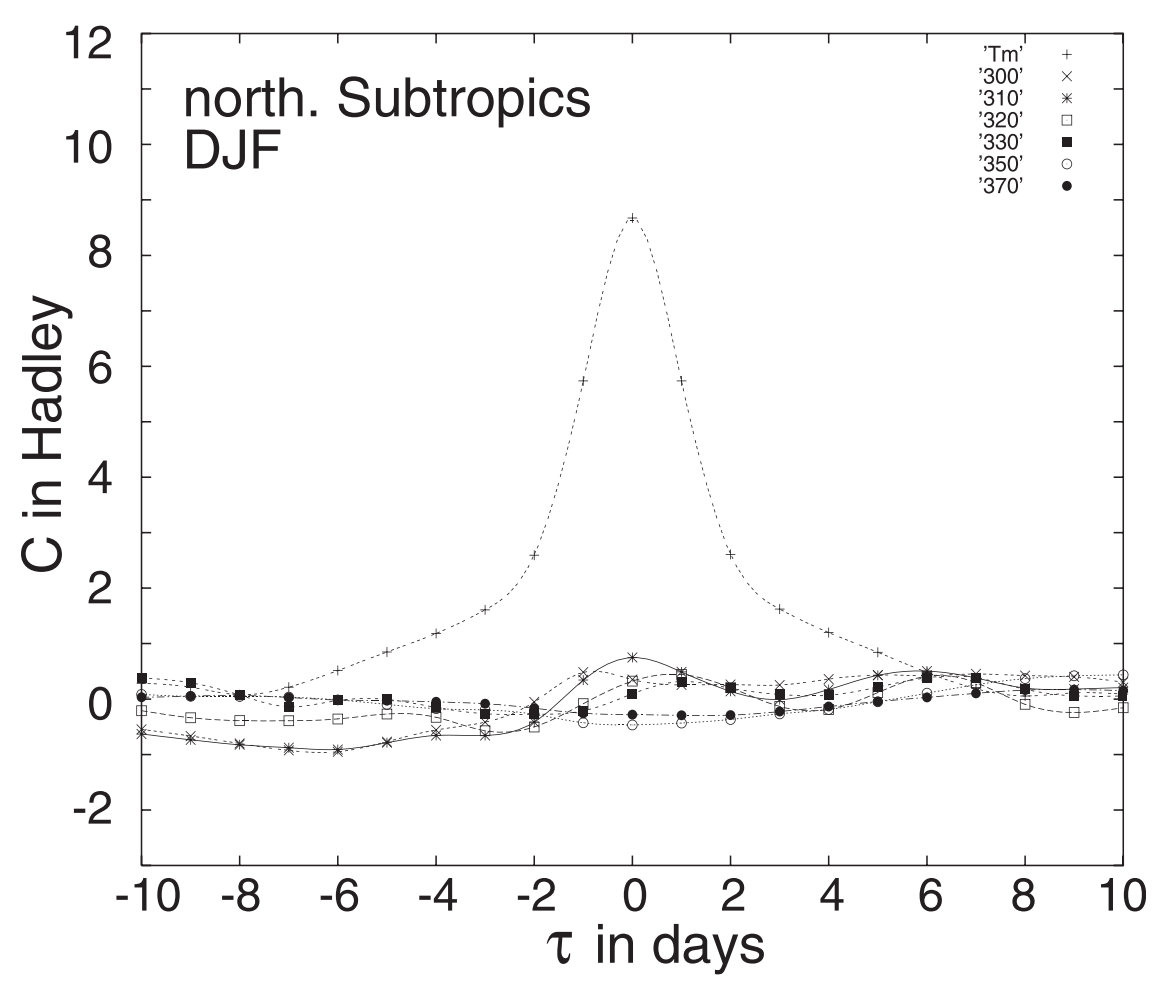

FIG. 6. As in Fig. 1, but for the northern subtropical belt in DJF.

-2 to -4 Hadley (Table 2). The covariance patterns (Fig. 7) do not show any connections between both torques.

\section{Discussion and conclusions}

We found for the polar belts and the northern midlatitude belt that the covariances of the mountain torque and the pressure torque tend to be negative for most isentropic surfaces and lags $|\tau|<5$ days. Thus, the pressure torque appears to be dynamically linked to the mountain torque in the sense that positive (negative) mountain torques occur in conjunction with negative (positive) pressure torques. The angular momentum exchanged at the earth tends to be transferred in the same direction in the atmosphere above. We find, moreover, that the pressure torque covariances decrease with increasing $\theta$. This implies that meridional transports supply the angular momentum, which is then transferred vertically by the pressure torques. To see these mechanism more clearly, let us write (1.1) in meridionally integrated abbreviated form:

$$
\frac{\partial}{\partial t} \mathrm{AAM}+\left.F_{h}\right|_{\varphi_{1}} ^{\varphi_{2}}+\left.F_{v}\right|^{\theta_{1}}=T_{p}+T_{m},
$$

where AAM is now the angular momentum of the belt and $F_{h}$ stands for the meridional fluxes through the boundaries at $\varphi=\varphi_{1}$ and $\varphi=\varphi_{2}$. Moreover, $F_{v}$ is the vertical transport at $\theta=\theta_{1}$ due to the heating. It is straightforward (e.g., Egger et al. 2007) to transform (3.1) into a covariance equation:

$$
\begin{aligned}
& \frac{\partial}{\partial \tau} C\left(T_{m}, \mathrm{AAM} \mid \tau\right)+C\left(T_{m},\left.F_{h}\right|_{\varphi_{1}} ^{\varphi_{2}} \mid \tau\right)+C\left(T_{m},\left.F_{v}\right|^{\theta_{1}} \mid \tau\right) \\
& \quad=C\left(T_{m}, T_{p} \mid \tau\right)+C\left(T_{m}, T_{m} \mid \tau\right)
\end{aligned}
$$

which relates the mountain torque to all other terms. We found in our analysis that the autocovariance $C\left(T_{m}, T_{m} \mid \tau\right)$ is always the largest term on the right-hand side of (3.2). The covariance $C\left(T_{m}, T_{p} \mid \tau\right)$ tends to be of opposite sign but never matches the autocovariance of $T_{m}$. The relation of the heating to the mountain torques has never been studied. It is presumably not large enough to establish a balance, at least at midlatitudes, nor is the friction torque omitted in (3.2). There is, however, also the problem discussed above that a reasonably exact evaluation of the pressure torques for $\theta$ surfaces that intersect the ground is complicated and can hardly be done satisfactorily. Czarnetzki and Johnson (1996) performed such a calculation for a case of lee cyclogenesis but had model data of appropriate resolution and accuracy available. This means that the estimates of $C\left(T_{m}, T_{p} \mid \tau\right)$ close to the ground in Figs. 1-7 are somewhat 


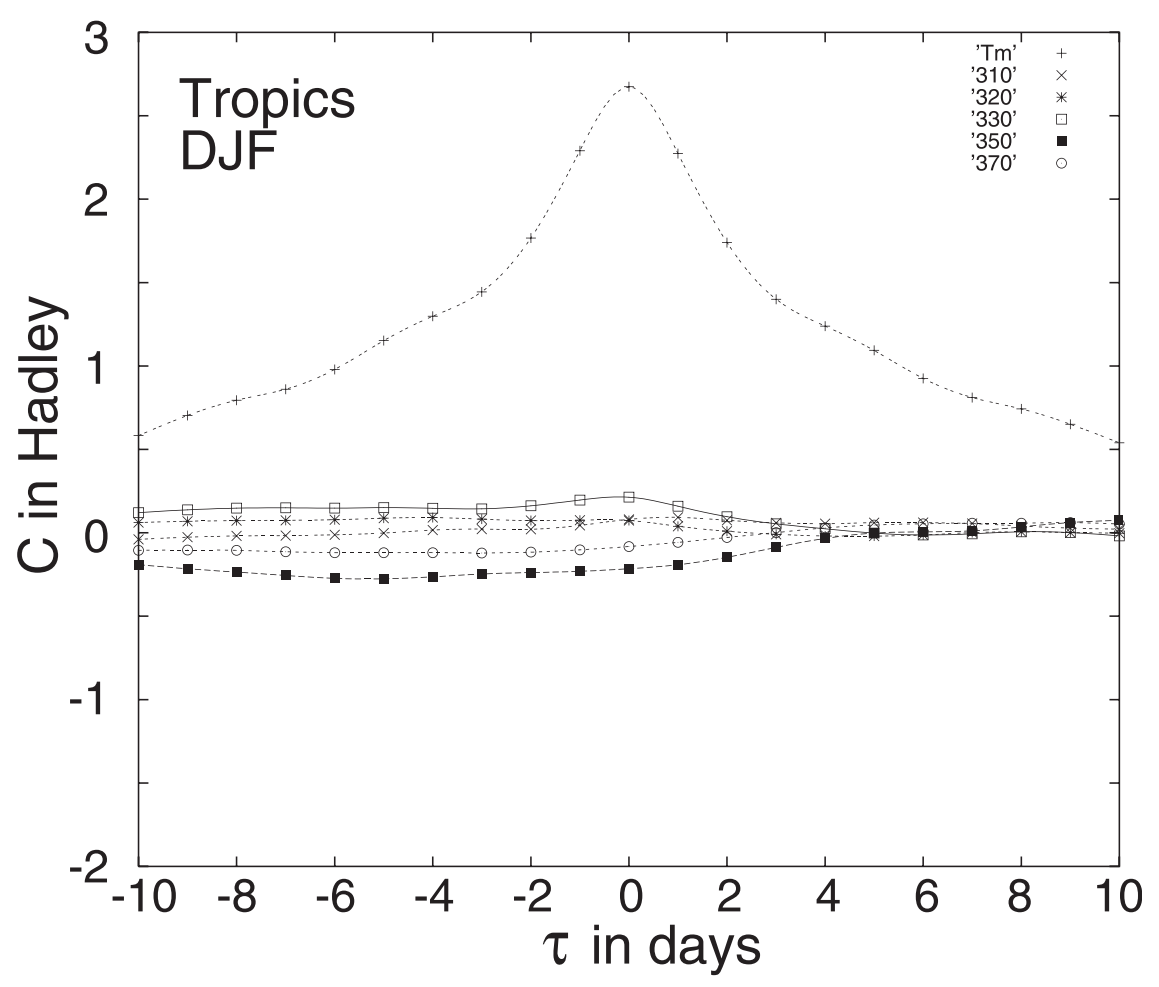

FIG. 7. As in Fig. 1, but for the tropical belt in DJF.

uncertain. Nevertheless, there is no reason to doubt the values obtained above the topography, and so our analysis suggests that much of the angular momentum transferred at the mountain is balanced by meridional transports and the tendency term.

The situation in the subtropical belts requires special attention. The observed situation in belt 3 may be explained by requiring strong low-level meridional transports and relatively large low-level tendencies although the analysis of Egger and Hoinka (2005) does not strongly support this view. However, Fig. 6 calls for a strong role of heating. It is difficult to see how else the budget in (3.2) can be satisfied.

Acknowledgments. The comments by both referees were very helpful.

\section{REFERENCES}

Andrews, D., 1983: A finite amplitude Eliassen-Palm theorem in isentropic coordinates. J. Atmos. Sci., 40, 1877-1883.

Czarnetzki, A., and D. Johnson, 1996: The role of terrain and pressure stresses in Rocky Mountain lee cyclones. Mon. Wea. Rev., 124, 553-570.

Davis, C. H., 1997: A modification of baroclinic waves by the Rocky Mountains. J. Atmos. Sci., 54, 848-860.
Egger, J., and K.-P. Hoinka, 2004: Axial angular momentum: Vertical fluxes and responses to torques. Mon. Wea. Rev., 132, 1860-1867.

$\longrightarrow$, and - 2005: Torques and the related fluxes of axial angular momentum. Mon. Wea. Rev., 133, 621-633.

— , and - 2008: The angular momentum budget of the TEM equations. J. Atmos. Sci., 65, 3305-3314.

—, K. Weickmann, and K.-P. Hoinka, 2007: Angular momentum in the global atmospheric circulation. Rev. Geophys., 45, RG4007, doi:10.1029/2006RG000213.

Gallimore, R., and D. Johnson, 1981: The forcing of the meridional circulation of the isentropic zonally average circumpolar vortex. J. Atmos. Sci., 38, 583-599.

Johnson, D., 1989: The forcing and maintenance of global monsoonal circulations: An isentropic analysis. Advances in Geophysics, Vol. 31, Academic Press, 43-316.

— , and W. Downey, 1975: The absolute angular momentum of storms: Quasi-Lagrangian diagnostics 2. Mon. Wea. Rev., 103, 1063-1076.

Juckes, M., I. James, and M. Blackburn, 1994: On the momentum budget of the southern extratropics. Quart. J. Roy. Meteor. Soc., 120, 1017-1044.

Lorenz, E., 1967: The nature and theory of the general circulation of the atmosphere. Rep. 218, TP115, WMO, Geneva, Switzerland, $161 \mathrm{pp}$.

Oort, A., and J. Peixoto, 1983: Global angular momentum and energy balance requirements from observations. Advances in Geophysics, Vol. 25, Academic Press, 355-490.

Townsend, R., and D. Johnson, 1985: A diagnostic study of the isentropic zonally averaged mass circulation during the GARP Global Experiment. J. Atmos. Sci., 42, 1565-1579. 